\title{
EARLY AMERICAN ENGLISH TRANSLATIONS OF EUROPEAN MEDICAL WORKS
}

\author{
by
}

\section{E. GASKELL}

A COMMONLY-HELD assumption is that to publish a catalogue of a library leads to an increase in the use of that library. The assumption is probably, though not necessarily, well grounded and difficult to refute; for it seems fairly self-evident that anything which serves to indicate the presence and availability of books in a certain place will tend to draw someone to them. Nevertheless, true though this statement might be in substance, it still needs some qualification; and the one which we wish to make here is that a catalogue's effectiveness can be seriously affected by its size. Size, of course, does not prevent a catalogue from identifying specific books accurately; but it can interfere with its secondary and less well recognized role of suggesting by implication some of the ways in which its contents might be studied in association.

All large catalogues, even those arranged by subject, suffer from this defect; which is why they need to be supplemented, and often are, by select lists (e.g. exhibition catalogues) of categories or types of material. In this way a library becomes anatomized and its topography laid out, with the result that its readers are brought to realize, through the suggestive power which any cohesive list of books must have, some of the potentialities for research in them. The library thus assumes a dynamic role in place of a passive or custodial one.

This perhaps unorthodox view of a library's function is the excuse for the following bibliography. Its contents (two thirds of which are in the Wellcome Library's American Collection) fall together in two respects: all were printed in America before 1821 (the date chosen by Austin ${ }^{1}$ to close the early period in American medicine), and all are native American English translations-preceding any which might have emerged from Britain - of works previously published in French, German, Italian and Latin. With one exception (item 20) reprints of British translations are excluded. As translations all these items are of course elements, and fairly important ones, in the continuing flow of ideas from one continent to another and they deserve to be studied on this footing; for they represent a desire and commitment on the part of their publishers and translators to introduce new work from abroad either on the grounds of its intrinsic worth or because it was thought specially relevant to American conditions. Quite often they are the only English translations made; and on occasions even when this is not so (e.g. Larrey) they remain the best.

The genesis of the bibliography was the acquisition by the Wellcome Library of a rare Americanum: an English translation, published in Philadelphia in 1818, of Edward Goodman Clarke's Medicinae Praxeos Compendium, London, 1799. Considered in isolation this pocket-sized epitome for medical students (see item 21) would deserve no special comment, notwithstanding that only three other copies

1 R. B. Austin, Early American Medical Imprints . . .1668-1820, Washington, U.S. Dept. of Health, etc. 1961 -alphabetically arranged and the basis for our own bibliography. 


\section{Texts and Documents}

are known to exist. ${ }^{2}$ But, in the belief that an object can only benefit from being seen in its environment, or in one of them, we have chosen to place it alongside other translations made in America in the period before 1821. At the same time we are well aware that this is not the only background in which the Compendium could be usefully considered: one might compare it, for instance, with the various students' texts which were used in American medical schools in the early nineteenth century. ${ }^{3}$ This we have not been able to do, nor is it in our terms of reference.

The effect of placing Clarke in such company as Bichat, Corvisart and Larrey is inevitably to lessen his own stature and to increase theirs; a comparison, we might add, which is unfair to him and one which ought never to be made. However, as we make plain in our description, his book for various reasons is not at all uninteresting and provokes, at the very least, speculation as to why and how it came to be printed as late as 1818 . If it does nothing else it has the special virtue of emphasizing-by contrast-the growing importance of French influences in American medical literature at that time.

In saying this we are only confirming what is already a fairly well-known fact: one to which Professor Shryock ${ }^{4}$ among others has alluded in his various essays on American medicine; and our object in redirecting attention to the subject is no more than to suggest it to the English readers of this journal as one worthy of further research, either in relation to the development of medical ideas' or to the general history of culture transference.

It might at this point be worth recalling Professor Shryock's opinion that French medical influences first began to assert themselves around 1810, the year in which the Eclectic Repertory (later the Journal of Foreign Medical Science) was founded in Philadelphia. Ten or eleven years later ${ }^{5}$ American medical journals and publishers

'Austin, op. cit., omits this work; but it is noted in Shaw and Shoemaker's American Bibliography, New York, Scarecrow Press, 1958-66, vol. 18.

s List of books recommended for medical students by the Massachusetts Medical Society in New Engl. J. Med. Surg., 1812, 1, 210-11.

'R. H. Shryock, Medicine and Society in America, 1660-1860, New York University Press, 1960. Also his Medicine in America: Historical Essays, Baltimore, Johns Hopkins Press, 1966, especially chapter 10 entitled 'The Advent of modern Medicine in Philadelphia, 1800-50'; and his American Medical Research, New York, Commonwealth Fund, 1947.

A classic general account of Franco-American relations at this period is Howard Mumford Jones' America and French Culture, 1750-1848, Chapel Hill, University of Carolina Press, 1927. Also relevant is the same author's $\boldsymbol{O}$ Strange New World, American Culture: the Formative Years, London, Chatto $\&$ Windus, 1965, in which he traces the ebb and flow in American sympathy for the French during the years following the War of Independence. It will be remembered that although the Americans at first welcomed the French revolution, as indeed did many Englishmen, their enthusiasm was very soon replaced by disenchantment with Napoleonic France and with Europe as a whole. The war between America and Britain in 1812 naturally reawakened some of the old pro-French sentiments, but it was not until 1815 that these could really be indulged. American medical students were then able to visit the Paris hospitals in increasing numbers, and did so along with a stream of young Englishmen.

Two American physicians who were in particularly close contact with France long before the end of the Napoleonic Wars were Benjamin Rush and Samuel L. Mitchell: both men having kept up a steady correspondence with one or two former French residents of America. (See Letters of Rush edited by L. H. Butterfield, 2 vols., Princeton University Press, 1951; and C. R. Hall, $A$ Scientist in the Early Republic: Samuel Latham Mitchell, 1764-1831, New York, Russell \& Russell, 1962).

${ }^{5}$ One of the numerous descriptions of France and French medicine written by American students and medical men in the early 1820s is F. J. Didier's Letters from Paris and other Cities of France, Holland, etc., New York, J. \& J. Harper, 1821. Didier also contributed an article entitled 'A sketch of the prevalent medical doctrines and of the hospitals at Paris' to the American Medical Recorder, $1821,4.473-81$, in which he talks approvingly of the new rationalism in French medicine, of the discoveries recently made by Laënnec, of traditional French skill in surgery (see the translations in our bibliography from Boyer, Desault and Larrey), and of her rich periodical literature. 


\section{Texts and Documents}

were transferring their attentions to a very marked extent from English to French models, ${ }^{6}$ driven to do so by the clinical progress then being made in the great French hospitals. ${ }^{7}$

Our own bibliography shows the process beginning a little earlier than 1810 with Charles Caldwell, who was responsible for a whole spate of translations between 1805 and 1807 (items 4-7). He was followed by such people as Tobias Watkins, Jacob Gates, the Nancrede brothers and J. G. Coffin. A fair amount of information is already known about the activities and influence of Caldwell, that scintillating but extremely quarrelsome man; but much less is known about his successors, and this seems a pity. These people after all had a most important role as intermediaries between an old and a young culture at a most critical point in the latter's development.

If these remarks on French influences are at all valid it might be interesting for someone to study, for instance, the particular effect made in America by the French experimentalists Bichat, Le Gallois and Magendie, ${ }^{8}$ none of whom incidentally had to contend with the formidable barriers which the Anglo-Saxon world erected against dissection and vivisection. To what extent were these breached? It is tempting also to speculate as to whether Beaumont's ${ }^{9}$ work was at all affected by the new currents flowing from France; as it is to wonder (in view of the translations from Cullen) for how long Cullenian influences persisted in America. A not altogether unrelated question for debate is how quickly the old patrician features in American medicine (at least nine out of the eighteen translators held M.D.s or other degrees from Pennsylvania) gave way to other more characteristically American ones. It is no small distance, temperamentally speaking, from Benjamin Rush to Daniel Drake, or from Philadelphia and Boston to Kentucky.

- J. S. Billings ('Century of American Medicine, 1776-1876', Amer. J. med. Sci., 1876, 72, 436-80) calculated that 101 translations from French works were made before 1842. It would be good to have a bibliography of them, and this we hope to produce on the lines of the present one.

The need to study foreign influence on American medicine is mentioned by Whitfield Bell in his Early American Science: Needs and Opportunities for Study, Williamsburg, Institute of Early American History and Culture, 1955, p. 28: 'Specifically what the historian should look for here is the American reception of the work of men who composed that brilliant galaxy of scientific geniuses at the end of the eighteenth and the beginning of the nineteenth centuries.'

7 E. Ackerknecht, Medicine at the Paris Hospital, 1794-1848, Baltimore, Johns Hopkins Press, 1967.

- Didier in the article previously cited has only scorn for the 'experiments on live animals by Magendie, and Legallois, for they prove scarcely anything but the cruelty of their authors, and show pretty clearly that they would be tolerably good executioners'. This distaste for experiment, which in Didier's case evidently sprang from an acute conscience, was a determining influence on both English and American medicine in the nineteenth century and helps to explain the continental dominance in this field. Shryock curiously fails to note this as a factor before the late nineteenth century though he does point out the ingrained Anglo-Saxon 'moral fervor' against dissection (American Medical Research, p. 20).

W. Beaumont, Experiments and Observations on the Gastric Juice, and the Physiology of Digestion, Pittsburgh, F. P. Allen, 1833. Beaumont was already reading medical books in 1808 whilst employed as village schoolmaster in Champlain, N.Y. (See W. Beaumont's Formative Years, by G. Miller, New York, H. Schuman, 1946) but there is no direct record of his having consulted French books. He is known to have used Haller's Physiology. 
Texts and Documents

LIST OF TRANSLATIONS

1. Cullen, W., Synopsis and Nosology, Hartford, 1792. (abridged from Genera Morborum in Synopsis Nosologiae Methodicae, Edinburgh, 1769)

Austin 580,581 ; not in WL

2. Cullen, W., Synopsis and Nosology, 2nd ed., Hartford, 1793. Almost identical with above.

Austin 582: not in WL

3. Cullen, W., Synopsis of Methodical Nosology, Philadelphia, 1793. (Unabridged from Genera Morborum, Edinburgh 1789.) Austin 584, 585; not in WL

4. Blumenbach, J. F., Elements of Physiology, Philadelphia, 1795. (From Institutiones Physiologicae, Göttingen, 1787.)

Translator: Charles Caldwell (1772-1853), M.D. Pennsylvania, 1796. John Elliotson published his own translation of the 3rd Latin ed. (Göttingen, 1810) in London in 1817 (2nd ed. London and Philadelphia 1817, see Austin 217). Caldwell, well-known firebrand and apologist for American self-sufficiency ('But the chief point . . . on which we have ground of self-gratulation, is the growing emancipation of our intellect as a people'-Autobiography, Philadelphia, 1855; reprinted New York, Da Capo Press, 1968) undertook his translation on Rush's advice in a lone attempt to make up the deficiency of English language works on physiology. His first intention had been to translate Haller. He adds notes of his own and an appendix on animal electricity. Austin 216; in WL

5. Desault, P. J., A Treatise on Fractures, Luxations and other Affections of the Bones, Philadelphia, 1805. (From Oeuvres chirurgicales, vol. 1, Paris, 1798. 2nd ed., Philadelphia 1811; 3rd ed., Philadelphia 1817.)

Translator: Charles Caldwell. Continued by E. D. Smith in 1814 (see item 14). Caldwell rates this work higher than Boyer's (see item 17) because of its general utility in rural conditions ("the practitioner . . . is generally obliged to be himself the constructor of the forms of apparatus which he uses'). Characteristically he declaims patriotically about his country's achievements in the arts and sciences, but he still manages to misdate his translation by six years in the catalogue of his writings appended to his Autobiography. Once again, as in item 4, he adds notes and an appendix. Austin 655; in WL

6. SenAC, J. B., A Treatise on the Hidden Nature and the Treatment of Intermitting and Remitting Fevers, Philadelphia, 1805. (From De Recondita Febrium cum Intermittentium tum Remittentium Natura et Curatione, Amsterdam, 1759.)

Translator: Charles Caldwell, who considered this work even better than Cleghorn's Epidemical Diseases in Minorca, London, 1751; Philadelphia 1809. Like the Nancredes (see item 13) he aimed to direct attention to the best of European medical literature, thereby lessening America's dependence on the British whose books were often inappropriate to American conditions. His sharp comments on the rivalry between French and English writers should be compared with the peevish preface which Waller attached to his London translation of Baron Larrey (see item 15). One wonders how justified was Caldwell's claim that national jealousies were causing French and English writers to live in deliberate ignorance of each other's works. He strangely omits this translation altogether from his list of publications in the Autobiography.

Austin 1731; in WL

7. Almert, J. L. M. A., A Treatise on Malignant Intermittents, 3rd ed., Philadelphia, 1807. (From Traité des Fièvres pernicieuses, Paris, 1804; 1st ed., 1799.)

Translator: Charles Caldwell, who shared Alibert's belief in the local, miasmatic origin of yellow fever, and considered that 'a competent knowledge of the principle laid in this work would, in the year 1793, have prevented the total mistakes into which many of the physicians of Philadelphia fell'. (1793 was the year in which Philadelphia suffered a catastrophic outbreak of yellow fever. The best description 


\section{Texts and Documents}

of it is to be found in J. H. Powell's Bring out your Dead, Philadelphia, University of Pennsylvania Press, 1949. It will be recalled that French immigrant physicians from St. Domingo, notably Jean Devèze, played a significant role in combating the epidemic.) The contrast which Caldwell draws between the prevailing French diet of vegetables and the rich, meaty American food is interesting and suggestive for future research. Austin 28; in WL

8. Calcagn, F., A Letter on the Inoculation of the Vaccina, practised in Sicily. Philadelphia, 1807. (From Lettera sulla Inoculazione della Vaccina praticata in Sicilia, Palermo, 1804.)

Translator: E. Cutbush (1772-1843), M.D. Penn. 1794, author of a pioneer work on military and naval medicine (see P. L. Pleadwell's article in Ann. med. Hist., 1923, 5, 337; and Ackerknecht's in J. Hist. Med. 1947, 2, 123.)

Austin 381; not in WL

9. Cullen, W., A Methodical System of Nosology, Stockbridge, 1808. (Unabridged from Genera Morborum; see also items 1-3.)

Translator: Eldad Lewis (d. 1825), prominent educator and protagonist for the medical profession in Lenox; founder of the town's library, and newspaper publisher. He passes disdainful comments on the Hartford abridgements (see items 1 \& 2) but seems unaware of the Wilkins text (see item 3) which had preceded the first British translation (Edinburgh, 1800) by seven years. The Lewis translation, then, comes relatively late in the field; but we include it in our bibliography because of Lewis's claim that he had already been using it in the classroom for years before it was actually published. In this connection it might be relevant to mention Caldwell's annotated edition (1816) of the First Lines of the Practice of Physic, Edinburgh 1784 (Austin 574) done at the request of Nathaniel Chapman who, according to Caldwell (Autobiography, p. 324) 'used it as his text book for ... ten or twelve years'. Cullen's influence in America has not yet been properly studied but when it is Chapman will be a central figure of interest. Interestingly enough the reviewer of his Discourses on the Elements of Therapeutics and Materia Medica, vol. 1, Philadelphia, 1817 (Amer. med. Recorder, 1818, 1, 188) makes the following comment: 'The works of Cullen, Lewis and Murray, although of undoubted reputation, have lost, to the American student at least, a good deal of their former interest. They abound in many opinions and theories which, in this country, are now pretty generally abandoned'.

Austin 578; in WL

10. Bichat, X., Physiological Researches upon Life and Death, Philadelphia, 1809. (From Recherches physiologiques sur la Vie et la Mort, 2nd ed., Paris, 1802; 1st ed., 1800.) Translator: Tobias Watkins (1780-1855), physician to the Marine Hospital of Baltimore and editor of the shortlived Baltimore Medical and Physical Recorder, 1808-9 (see H. W. Jones 'A hospital inspector's diary, being an account of the journey of Tobias Watkins . . . in the year 1818', Bull. Hist. Med., 1939, 7, 210-35.) This translation should be considered along with item 13, as their appearance in America so soon after their first publication in France betokens a keen appreciation of the way in which physiology was developing at that time. A much less fluent translation of Bichat, by F. Gold, was published in London in 1815.

\section{Austin 203; in WL}

11. Corvisart, J. N., An Essay on the Organic Diseases and Lesions of the Heart and Great Vessels, Boston, 1812. (From Essai sur les Maladies et les Lésions organiques du Coeur et des Gros Vaisseaux, Paris, 1806.)

Translator: Jacob Gates (dates unknown), member of the Massachusetts Medical Society. Reviewed in the New Engl. J. Med. Surg., 1812, 1, 292-301, where the translator is attacked for his inaccuracies. A rather better translation was published in London in 1813: translator, C. H. Hebb. But the priority is still America's. American interest in heart diseases is also attested by the translation of Pelletan's 


\section{Texts and Documents}

article, entitled 'Memoir of the Diseases of the Heart', which appeared in the New Engl. J. Med. Surg., 1813, 2, 140-52.

Austin 548; in WL

12. Bichat, X., A Treatise on the Membranes in General, and on Different Membranes in Particular, Boston, 1813. (From Traité des Membranes en général et de diverses Membranes en particulier, 2nd ed., Paris, 1802; 1st ed., 1800.)

Translator: J. G. Coffin (1770-1829) who also wrote on the history of the Boston Dispensary (Austin 489), cold and warm bathing (Austin 490), teeth (Austin 491) and medical education (published in Boston in 1822). He also translated a work by Brera (see item 19).

\section{Austin 204; in WL}

13. LE Gallors, J. J. C., Experiments on the Principle of Life, and Particularly on the Principle of the Motions of the Heart, and on the Seat of this Principle, Philadelphia, 1813. (From Expériences sur le Principe de la Vie, Paris, 1812.)

Translators: the brothers N. C. \& J. G. Nancrede, American-born sons of Paul Joseph Guerard Nancrede, a one-time soldier in the French Army who had served in America under Rochambeau. The Nancrede brothers had both studied in Philadelphia and in Paris where, so they claimed, they helped Le Gallois in his experiments. The results of these were first noticed in vol. 1, p. 203 of the New Engl. J. Med. Surg., 1812, and then, two years later, by a lengthy abstract (ibid., 1814, 3, 11-20): subsequently by two reviews (ibid., 1814, 3, 383-400; 1815, 4, 60-74). It is worth quoting a few lines from the latter: 'If we felt a pride in seeing this important work first translated into English in our own country, this pride was increased by noticing that the translators were natives of this place. . . . We have been the more particular in speaking of these young gentlemen, because it seems to be their intention to continue to give us whatever else may come from the same source, and because also, they must be qualified to translate some of the other important and valuable medical works which are to be found in the French language, and the diffusion of which, in this country, would be highly useful'. In their preface to the Experiments the translators contend that several Philadelphia professors were well acquainted with the work of Le Gallois in its original form. Evidence of its effect in the medical schools is the dissertation presented by Lafayette Perkins at Harvard on 25 August 1814, entitled 'On some of the Experiments on the Principle of Life ... which were preformed by Dr. Le Gallois', New Engl. J. Med. Surg., 1814, 3, 401. Austin 1139; not in WL

14. Desault, P. J., The Surgical Works, or Statement of the Doctrine and Practice of P. J. Desault, 2 vols., Philadelphia, 1814. (From Oeuvres chirurgicales, vol. 2 \& 3, Paris, 1798-1803. A continuation of Caldwell's translation (see item 5.)

Translator: Edward Darrell Smith (1777-1819), M.D. Penn., 1800. Reviewed in Philad. med. Museum, 1805, 1, 475-79.

Austin 654; not in WL

15. LARRey, D. J., Baron, Memoirs of Military Surgery, and Campaigns of the French Armies, on the Rhine, etc. 2 vols., Baltimore, 1814. (From Mémoires de Chirurgie militaire et Campagnes, 2nd ed., vols. 1-3, Paris, 1812).

Translator: Richard Wilmott Hall (1785-1847), M.D. Penn., 1806, and professor of obstetrics in the University of Maryland. Hall had unbounded admiration for Larrey, unlike the Englishman John Waller who produced an abridged translation the following year in London containing shameful denigrations of the Frenchman's ability. Comparison between the two translations reveals a great deal about national attitudes. Austin 1123; in WL

16. SwediAUR, F. X., A Complete Treatise on the Symptoms, Effects, Nature and Treatment of Syphilis, Philadelphia, 1815. (From Traité complet sur les Symptômes . . . des Maladies siphilitiques, 4th ed., Paris, 1801, 2 vols.)

Translator: T. T. Hewson (1773-1848), son of the English anatomist William. The 


\section{Texts and Documents}

3rd Edinburgh English edition (1788) contains a now famous chapter on a new form of venereal disease in Canada. Hewson frankly admits to having borrowed extensively from that edition. He was physician to the Walnut St. Prison for 12 years (1806 to 1818), professor of comparative anatomy in the University of Pennsylvania and the founder of a private medical school.

Austin 1840; not in WL

17. BOYRR, A., A Treatise on Surgical Diseases, and the Operations suited to them, New York, 1815-6, 2 vols. (From Traité des Maladies chirurgicales et des Opérations qui leur conviennent, Paris, 1814,4 vols.)

Translator: A. H. Stevens (1789-1869), M.D. Penn., 1811, and later a noted New York surgeon. His compressed version of Boyer's work, conveying 'the spirit rather than the letter', is supplemented by notes. Stevens, an intensely patriotic man, had been twice imprisoned by the British. Like Caldwell he expresses irritation at European rivalries ('the jealousy and rivalship of the French and English surgeons have extended to the remotest ramifications in medical science') and claims to give an impartial view of European practice as a whole-adding a few American improvements for good measure. Austin 262; in WL

18. Lieutaud, J., Synopsis of the Universal Practice of Medicine, Philadelphia, 1816. (from Synopsis Universae Praxeos Medicae, Amsterdam, 1765, Part 1).

Translator: Edwin A. Atlee (1776-1852), M.D. Penn., 1804. His object in resuscitating this old work was to provide a 'useful Family Physician'. One wonders how he obtained the support (as he claims he did) of several leading physicians.

Austin 1150; not in WL

19. Brera, V. L., A Treatise on Verminous Diseases, Boston, 1817. (from Traité des Maladies vermineuses, Paris, 1804; originally published in Crema, 1798.)

Translator: J. G. Coffin (see item 12). Addressed to the medical students of Harvard: 'there is no systematic treatise on this subject in English', and containing extensive additions relative to recent American and English literature. Reviewed in New Engl. J. Med. Surg., 1817, 6, 385-93.

Austin 270; in WL

20. Orfila, M. J. B., A General System of Toxicology, Philadelphia, 1817. (Abridged from Traité des Poisons . . ou Toxicologie générale, Paris, 1814-15, 2 vols.)

Translator: J. G. Nancrede (see item 13). On the grounds that this abridgement is taken word for word from the London translation of 1816 we ought not to include it in our bibliography; but we do so because of the positive way in which Nancrede expresses his feelings of patriotism. To him the Europeans compared most unfavourably with freedom-loving Americans. America, he says, is a country where the 'good of the community, not the private interest of individuals, is uniformly the object of public institutions'. Even more intemperately he boasts that 'our literary and scientific establishments are for us, not for them. They emerged from a state of barbarism; they were ignorant; we are civilised; we are learned'.

\section{Austin 1438; in WL}

21. Clarke, E. G., Compendium of the Practice of Physic; pointing out the Symptoms, Causes, Diagnoses, Prognoses, and Method of Cure of Diseases, Philadelphia, James Webster, 1818. (From Medicinae Praxeos Compendium, London 1799, 4th ed., 1809.)

Translator: R. W. Worthington. Clarke was one of London's more colourful if less reputable author-physicians (d. 1810) whose career is touched upon by his former teacher Sir Astley Cooper (see B. B. Cooper's Life of Sir Astley Cooper, London, 1843 , vol. 1, p. 146). He also receives a short notice in the D.N.B., vol. 10, p. 424, London, 1887). His Compendium, which was based on Cullen's Nosologia Methodica, was praised in the London med. Rev., 1799, 1, 453, as was its 2nd edition, ibid., 1802, 8, 281 ('a neat and accurate account of diseases ... [which] may be highly useful to such as are about to submit themselves to the ordeal of a Latin medical examination'). 


\section{Texts and Documents}

His other books are the Modern Practice of Physic, London, 1805 (7th ed. entitled The New London Practice of Physic, London, 1811) and abridged Latin and English versions of the three British pharmacopaeias (Pharm. Coll. Reg. Lond., Edin. et Eblanae. Conspectus Medicus, London, 1811; Conspectus of the London. Edin. and Dublin Pharmacopoeias, London, 1811, 2nd editions came out respectively in 1816 and 1814.)

The Compendium's first appearance in a language other than Latin was in 1805 when Arcangelo Spedalieri turned it into Italian. Ten years later he used it as the basis for a two-volume work with much additional material. The American translation was done by an expatriate English naval surgeon who had settled in Philadelphia. So far as we can discover he wrote no other book and contributed only one article; by an astonishing coincidence his name is written in the Wellcome Library's copy of the very journal in which this article was published ('Some observations on inflammation', Amer. med. Recorder, 1818, 1, 340-61). Worthington dedicates his translation to Nathaniel Chapman. The pages are liberally scattered with annotations of his own, and there is also an appendix in the form of a translated extract on yellow fever from Sauvages de la Croix (Nosologie Méthodique, T. 1, pp. 412-6, Paris 1771). Not in Austin; in WL

22. Richerand, A. B., Account of a Resection of the Ribs and the Pleura, Philadelphia, 1818. (from Histoire d'une Résection des Côtes et de la Plèvre, Paris, 1818).

Translator: Thos. Wilson (dates unknown) who also translated the next item. Austin 1602; not in WL

23. Rucco, G., A Dissertation on the General Principle of Anatomy and Comparative Physiology, as Applied to the Science of Medicine, Philadelphia, 1818. (From an Italian text never published.)

Translator: Thos. Wilson.

Austin 1630; not in WL

24. TOURTELle, E., The Principles of Health (Elements of Hygiene) or, A Treatise on the Influence of Physical and Moral Causes on Man, and on the Means of Preserving Health, Baltimore, 1819, 2 vols. (From Elémens d'Hygiène, 2nd ed., Strasbourg, 1802, 1st. ed., 1797.)

Translator: G. Williamson (dates unknown), member of the Medical and Chirurgical Faculty of Maryland. He adds two of his own sections (on education and onanism) and forecasts without enthusiasm that certain of the less desirable features of European life (e.g. viniculture) will before long flourish in America-'And it is to be feared that it will acquire a part of the attention that ought to be paid to articles more essential to life'.

Austin 1917; in WL

25. Magendie, F., Physiological and Chemical Researches on the Use of the Prussic or Hydrocyanic Acid in the Treatment of Diseases of the Breast. New Haven, 1820. (From Recherches physiologiques et cliniques sur l'Emploi de l'Acide prussique etc., Paris, 1819.)

Translator: James Gates Percival (1795-1856), poet-physician, book-collector, army surgeon and state geologist of Wisconsin. His counterpart in England as a popularizer of prussic acid was Dr. A. B. Granville. (Further Observations on the Hydrocyanic Acid, London, 1819). On the life of Percival consult H. Thoms in Bull. Soc. Med. Hist., Chicago, 1919, 22, 2, 219; and F. H. Cogswell's J. G. Percival and his Friends, New Haven, 1902. The Nancrede brothers had already translated a paper of Magendie and Pelletier on ipecacuanha (Amer. med. Recorder, 1818, 1, 98-112.) Austin 1183; in WL 